\title{
A randomized, double-blind, four-arm parallel-group study of the efficacy and safety of azelnidipine and olmesartan medoxomil combination therapy compared with each monotherapy in Japanese patients with essential hypertension: the REZALT study
}

\author{
Toshio Ogihara ${ }^{1}$, Takao Saruta ${ }^{2}$, Kazuyuki Shimada ${ }^{3}$ and Kizuku Kuramoto ${ }^{4}$
}

A 12-week randomized, double-blind, four-arm parallel-group, comparative study was conducted in patients with essential hypertension to evaluate the antihypertensive effect and safety of combination therapy with olmesartan medoxomil (OLM, an angiotensin-receptor blocker) $20 \mathrm{mg}$ plus azelnidipine (AZL, a long-acting dihydropyridine calcium channel blocker) $16 \mathrm{mg}$, (O/A (20/16)), or OLM $10 \mathrm{mg} / \mathrm{AZL} 8 \mathrm{mg}(0 / \mathrm{A}(10 / 8))$ compared with those of monotherapy with OLM $20 \mathrm{mg}(\mathrm{OLM}$ (20)) or AZL $16 \mathrm{mg}$ (AZL (16)). The change from baseline to week 12 in seated blood pressure (SeBP) was $-23.6 /-14.2 \mathrm{~mm} \mathrm{Hg}$ (systolic/diastolic BP) in the O/A (20/16) group, and $-20.3 /-13.0 \mathrm{~mm} \mathrm{Hg}$ in the O/A (10/8) group, which was a significantly greater reduction in SeBP than in the monotherapy groups $(-15.7 /-9.9 \mathrm{~mm} \mathrm{Hg}$ in OLM (20); $-15.0 /-9.4 \mathrm{~mm} \mathrm{Hg}$ in AZL (16)). The change from baseline in 24-h ambulatory BP was also significantly greater in the $\mathrm{O} / \mathrm{A}(20 / 16)$ and $\mathrm{O} / \mathrm{A}(10 / 8)$ combination groups $(-22.1 /-13.5$ and $-18.2 /-10.6 \mathrm{~mm} \mathrm{Hg}$, respectively) than in the OLM (20) and AZL (16) monotherapy groups $(-12.1 /-6.9$ and $-12.0 /-6.9 \mathrm{~mm} \mathrm{Hg})$. The proportion of patients achieving the SeBP goal $(<130 / 85 \mathrm{~mm} \mathrm{Hg}$ for normal BP or $<140 / 90 \mathrm{~mm} \mathrm{Hg}$ for high-normal BP) was significantly higher in the O/A (20/16) combination group than in the monotherapy groups. The incidence of adverse events was similar in the O/A combination groups and the monotherapy groups. These results showed that combination therapy with $\mathrm{O} / \mathrm{A}$ was well tolerated and exerted a stronger antihypertensive effect compared with monotherapy with OLM or AZL in patients with essential hypertension. Hypertension Research (2009) 32, 1148-1154; doi:10.1038/hr.2009.163; published online 9 October 2009

Keywords: ambulatory blood pressure monitoring; azelnidipine; combination therapy; essential hypertension; olmesartan medoxomil

\section{INTRODUCTION}

Hypertension is an important risk factor for cardiovascular and cerebrovascular diseases. ${ }^{1}$ The goal of antihypertensive treatment is to prevent cerebrovascular and cardiovascular diseases by appropriate blood pressure (BP) control. In many countries, however, BP is not adequately controlled in more than $50 \%$ of patients. ${ }^{2-4}$ Generally, multiple factors are considered responsible for hypertension; therefore, in many cases, two or more drugs with different mechanisms of action are required to achieve BP control. ${ }^{2,4}$ The guidelines for the management of hypertension in Japan, the United States and Europe recommend considering a combination of two drugs at the beginning of treatment in patients with high-risk hypertension or grades II-III hypertension..$^{2,4,5}$
An angiotensin-receptor blocker (ARB) plus a calcium channel blocker $(\mathrm{CCB})$ is one of the antihypertensive combinations recommended in the JSH2009..$^{5}$ This ARB/CCB combination therapy is reported to be highly effective compared with high-dose monotherapy. ${ }^{6,7}$ Previous studies suggested that in addition to the antihypertensive effect, ARBs might directly prevent organ damage, for example, by protecting the heart through regression of left ventricular hypertrophy, or by protecting the kidney through decreasing proteinuria. ${ }^{8,9}$ Similarly, dihydropyridine CCBs might have organ-protective effects (that is, regression of left ventricular hypertrophy or inhibition of the progression of atherosclerosis). ${ }^{10,11}$ The ACCOMPLISH study demonstrated that treatment with an angiotensin-converting enzyme inhibitor plus a CCB was associated with a $20 \%$ reduction in

\footnotetext{
${ }^{1}$ Osaka General Medical Center, Osaka Prefectural Hospital Organization, Osaka, Japan; ${ }^{2}$ Department of Internal Medicine, School of Medicine, Keio University, Tokyo, Japan; ${ }^{3}$ Department of Medicine, Jichi Medical University, Tochigi, Japan and 4 Tokyo Metropolitan Geriatric Hospital and Institute of Gerontology, Tokyo, Japan Correspondence: Dr T Ogihara, Osaka General Medical Center, Osaka Prefectural Hospital Organization, 3-1-56, Bandai-Higashi, Sumiyoshi-ku, Osaka 558-8558, Japan. E-mail: ogiharat@opho.jp

Received 26 August 2009; accepted 27 August 2009; published online 9 October 2009
} 
cardiovascular morbidity and mortality in high-risk patients, relative to angiotensin-converting enzyme inhibitor/diuretic therapy. ${ }^{12}$ These findings suggest that the combination of a renin-angiotensin system inhibitor and a CCB may be effective in preventing cardiovascular events. As stated above, the combination of a renin-angiotensin system inhibitor, such as an ARB, and a CCB exerts an excellent antihypertensive effect and may inhibit cardiovascular events. According to a survey of prescriptions for hypertension in Japan, ARB plus CCB is the most common combination among all prescriptions. ${ }^{13}$

We investigated the antihypertensive effect of combination therapy (O/A) with olmesartan medoxomil (OLM), an ARB, and azelnidipine (AZL), a long-acting dihydropyridine CCB. We evaluated the efficacy and safety of 12-week O/A combination therapy compared with OLM or AZL monotherapy in Japanese patients with essential hypertension. As 24-h BP control has become increasingly important in recent years, the antihypertensive effect of O/A was evaluated by ambulatory $\mathrm{BP}$ monitoring $(\mathrm{ABPM})$ in addition to conventional cuff BP measurement.

\section{METHODS}

\section{Subjects}

Male and female outpatients with essential hypertension who met the following criteria were enrolled: age $\geqslant 20$ years; mean of the seated $\mathrm{BP}$ (SeBP) in the clinic at the last two visits during the run-in period: systolic BP $(\mathrm{SBP}) \geqslant 140$ to $<180 \mathrm{~mm} \mathrm{Hg}$ and diastolic BP (DBP) $\geqslant 90$ to $<110 \mathrm{~mm} \mathrm{Hg}$; 24 -h ambulatory $\mathrm{BP}$ in the run-in period: $\mathrm{SBP} \geqslant 135$ and $\mathrm{DBP} \geqslant 80 \mathrm{~mm} \mathrm{Hg}$. Main exclusion criteria were as follows: secondary or malignant hypertension, myocardial infarction or cerebrovascular disorder within 3 months before informed consent, unstable angina pectoris, severe heart failure (NYHA class III or IV), serious arrhythmia (grade II or III atrioventricular block), requiring treatment for malignant tumors, bradycardia, hepatic function disorder, renal function disorder or poorly controlled diabetes.

This study was conducted according to the principles of the Declaration of Helsinki and Good Clinical Practices. This study was approved by the Institutional Review Board of each study site before implementation. Each participant gave written informed consent for this study before participation. This study is registered as ID number JapicCTI-060286 at the Japan Pharmaceutical Information Center.

\section{Study design}

The study design is shown in Figure 1. This was a multicenter, randomized, double-blind, four-arm parallel-group, comparative study consisting of a 4week placebo run-in period and a 12-week double-blind treatment period. Patients visited the study site at the beginning, at week 3 , and at the end of the run-in period; at weeks 2, 4, 6, 8, 10 and 12 of the treatment period; and the day after completion of treatment. Patients were randomly assigned to the following four treatments: AZL $16 \mathrm{mg}$ (AZL (16)) or OLM $20 \mathrm{mg}$ (OLM (20)) as monotherapy, or OLM $10 \mathrm{mg} / \mathrm{AZL} 8 \mathrm{mg}(\mathrm{O} / \mathrm{A}(10 / 8))$ or OLM $20 \mathrm{mg} / \mathrm{AZL}$

Double-blind treatment period

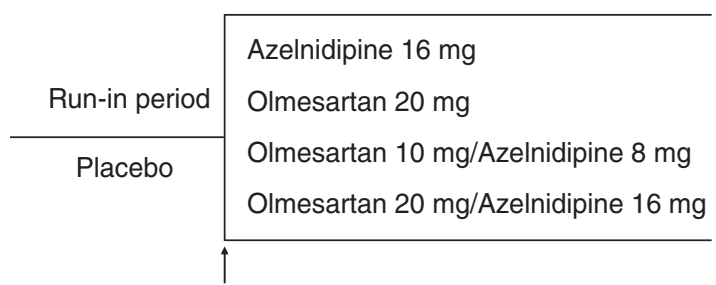

Randomization

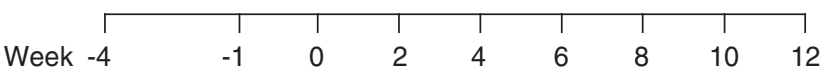

Figure 1 Study design.
$16 \mathrm{mg}(\mathrm{O} / \mathrm{A}(20 / 16))$ as combination therapy. They took the study drugs once daily after breakfast.

\section{Study assessments}

Vital signs and physical findings were recorded at every visit. SeBP was measured by auscultation using a mercury sphygmomanometer. BP was measured three times with 1 or 2 -min intervals at trough $(24 \pm 3 \mathrm{~h}$ post-dose); the mean value of these three measurements was used for analysis. Twentyfour-hour ABPM was performed during the run-in period and on week 12 during the treatment period. Using a validated ABPM device (TM-2431, A\&D, Tokyo, Japan), SBP, DBP and pulse rate (PR) were continuously measured and recorded for more than $25 \mathrm{~h}$ in 30 -min intervals. Laboratory examinations (hematology, blood biochemistry and urinalysis) were performed during the run-in period and at completion of the treatment period.

\section{Study end point}

Primary end point was the change from baseline in SeBP (SBP and DBP) at study end. SeBP during the run-in period was defined as the mean of BP at the last two visits, and SeBP at study end was defined as the mean of BP at the last two visits during the treatment period. Secondary end points were as follows: proportion of patients achieving the SeBP goal (SBP/DBP $<130 / 85 \mathrm{~mm} \mathrm{Hg}$, criteria for normal BP by cuff measurement) at study end, the change from baseline in the clinic seated PR at study end and the change from baseline in 24-h ambulatory BP at study end. In addition, the following values at study end were defined as post hoc end points: proportion of patients achieving the SeBP goal (SBP/DBP $<140 / 90 \mathrm{~mm} \mathrm{Hg}$, criteria for high-normal BP by cuff measurement); proportion of patients achieving SBP/DBP $<140 / 90 \mathrm{~mm} \mathrm{Hg}$ classified by age ( $<65$ years, $\geqslant 65$ years); and responder rate (the proportion of patients with clinic SBP/DBP $<140 / 90 \mathrm{~mm} \mathrm{Hg}$; or with either clinic SBP decreased $>20 \mathrm{~mm} \mathrm{Hg}$ or clinic DBP decreased $>10 \mathrm{~mm} \mathrm{Hg}$, and mean BP (that is, $(\mathrm{SBP}+2 \mathrm{DBP}) / 3)$ decreased $>13 \mathrm{~mm} \mathrm{Hg})$. The safety end points were defined as the incidence of adverse events (AEs).

\section{Statistical analysis}

A sample size of 180 patients per group would have $90 \%$ power to detect all the differences of 6 and $3 \mathrm{~mm} \mathrm{Hg}$ in the primary SBP and DBP end points between the O/A (20/16) group and the monotherapy (AZL (16) or OLM (20)) group assuming that the common s.d. would be 11 and $8 \mathrm{~mm} \mathrm{Hg}$, respectively, and the correlation coefficient between SBP and DBP would be 0.7 using 2000 simulations of a $t$-test with a 0.05 two-sided significance level. The number of patients was determined to be 190 for each group in consideration of possible withdrawals.

Patients included for the primary efficacy analysis were the full analysis set. The safety analysis set was patients who received the study drug at least once during the treatment period.

In the treatment comparison for the SeBP (primary end point), $P$-values were calculated by an analysis of covariance with SeBP value at baseline, gender and weight as covariates. The adjusted mean value for each treatment group and the $95 \%$ confidence interval were also calculated. In the comparison for the proportion of patients achieving the SeBP goal, logistic regression was performed with the severity of hypertension at baseline, gender and weight as covariates. Subsequently, adjusted odds ratios, $P$-values between treatment groups and the $95 \%$ confidence intervals were calculated. Subgroup (gender, weight ( $<67.5 \mathrm{~kg}, \geqslant 67.5 \mathrm{~kg}$ ), age ( $<65$ years, $\geqslant 65$ years), severity of hypertension (grade I or II) and complication (hyperlipidemia, hyperuricemia and diabetes)) analyses of primary end point were conducted. All statistical analyses were performed using SAS version 8.02 (SAS Institute, Cary, NC, USA).

\section{RESULTS}

\section{Study population}

Of 1206 patients who gave consent, 1202 participated in the run-in period of the study. Subsequently, 867 out of 1202 patients were randomized and assigned to one of the four treatments (AZL (16), $n=217$; OLM (20), $n=213$; O/A (10/8), $n=222$; O/A (20/16), $n=215)$. 
Three hundred and thirty five patients were dropped in the run-in period, mainly due to failure to meet the eligibility criteria $(n=226)$, withdrawal of consent $(n=54)$ and occurrence of AEs $(n=14)$. Of the 867 patients advanced to the treatment period, 862 patients were included in the full analysis set, and 866 patients were included in the safety analysis set. Five patients were excluded from the full analysis set (AZL (16), $n=1$; OLM (20), $n=2$; O/A (10/8), $n=1$; O/A (20/16), $n=1)$ mainly due to lack of SeBP data after randomization. The baseline characteristics are shown in Table 1. There were no major differences in age, gender, BP, weight, body mass index, complications and severity of hypertension among all groups.

\section{Efficacy}

The change from baseline in SeBP at study end in each group is shown in Figure 2a. These changes were $-15.0 /-9.4 \mathrm{~mm} \mathrm{Hg}$ (SBP/DBP) in the AZL (16) group, $-15.7 /-9.9 \mathrm{~mm} \mathrm{Hg}$ in the OLM (20) group, $-20.3 /-13.0 \mathrm{mmHg}$ in the O/A (10/8) group and -23.6/ $-14.2 \mathrm{~mm} \mathrm{Hg}$ in the O/A (20/16) group. The change from baseline in 24-h BP by ABPM is shown in Figure $2 \mathrm{~b}$. These changes were $-12.0 /-6.9 \mathrm{~mm} \mathrm{Hg}$ (SBP/DBP) in the AZL (16) group, -12.1/ $-6.9 \mathrm{~mm} \mathrm{Hg}$ in the OLM (20) group, $-18.2 /-10.6 \mathrm{~mm} \mathrm{Hg}$ in the $\mathrm{O} / \mathrm{A}(10 / 8)$ group and $-22.1 /-13.5 \mathrm{~mm} \mathrm{Hg}$ in the O/A (20/16) group. SeBP and 24-h BP reductions in the O/A (20/16) and O/A (10/8) combination groups were significantly greater than those in the monotherapy groups. BP reduction in the O/A (20/16) group was greater than that in the O/A (10/8) group.

Changes in SeBP over 12 weeks are illustrated in Figure 3. In all treatment groups, both SBP and DBP decreased from the start of treatment to week 2. Particularly, SBP and DBP in the combination groups decreased by more than 15 and $10 \mathrm{~mm} \mathrm{Hg}$ at week 2, respectively. A stable antihypertensive effect was observed throughout the study period, and O/A (20/16) combination therapy showed the greatest effect.
The proportion of patients achieving the SeBP goal (SBP/ $\mathrm{DBP}<130 / 85 \mathrm{~mm} \mathrm{Hg}$ or $<140 / 90 \mathrm{~mm} \mathrm{Hg}$ ) at study end is shown in Figure 4. The proportion of patients achieving the SeBP goal in the O/A (20/16) combination group was significantly higher than in the monotherapy groups $(P \leqslant 0.0011)$. The responder rates were $53.2 \%$ in the AZL (16) group, 59.2\% in the OLM (20) group, $75.1 \%$ in the O/A (10/8) group and $82.7 \%$ in the O/A (20/16) group.

The adjusted mean change from baseline in the seated PR at study end was -1.4 b.p.m. in the AZL (16) group, 0.9 b.p.m. in the OLM (20) group, -0.3 b.p.m. in the O/A (10/8) group and -1.1 b.p.m. in the O/A (20/16) group. The PRs were slightly decreased in the O/A (20/16), O/A (10/8) and AZL (16) groups. There were significant differences between either the O/A (20/16) or O/A (10/8) group and the OLM (20) group. The PR changed little in any group throughout the study; however, it tended to decrease in the AZL (16), O/A (10/8) and O/A (20/16) groups (Figure 3c).

Seated BP reduction and BP goal achievement at the study end was analyzed for each subgroup. In terms of gender and weight, the antihypertensive effect seemed greater in females and in lower bodyweight patients, but this was considered to have no clinically significant influence. There were also no clinically significant differences among other subgroups in any treatment group. Thus, O/A combination showed a strong antihypertensive effect regardless of patient background factors (gender, weight, age, severity of hypertension and complication).

\section{Safety}

The number of patients who experienced AEs is summarized in Table 2. The incidence of AEs in the AZL (16), OLM (20), O/A $(10 / 8)$ and O/A (20/16) groups was 58.1, 59.6, 52.0 and 57.7\%, respectively. Among the above, the incidence of drug-related AEs (as assessed by the investigators) was 15.7\% (AZL (16)), 10.8\% (OLM (20)), $6.8 \%(\mathrm{O} / \mathrm{A}(10 / 8))$ and $10.2 \% \mathrm{O} / \mathrm{A}(20 / 16))$. The main drug-

Table 1 Demographic and baseline clinical characteristics of the study patients (FAS)

\begin{tabular}{|c|c|c|c|c|c|}
\hline & $\begin{array}{l}A Z L(16) \\
(\mathrm{n}=216)\end{array}$ & $\begin{array}{l}\text { OLM (20) } \\
(\mathrm{n}=211)\end{array}$ & $\begin{array}{c}O / A(10 / 8) \\
(n=221)\end{array}$ & $\begin{array}{c}O / A(20 / 16) \\
(n=214)\end{array}$ & $\begin{array}{c}A / l \\
(\mathrm{n}=862)\end{array}$ \\
\hline Age (years) ${ }^{a}$ & $56.7 \pm 10.6$ & $57.4 \pm 11.0$ & $56.6 \pm 9.9$ & $55.7 \pm 10.4$ & $56.6 \pm 10.5$ \\
\hline \multicolumn{6}{|l|}{ Gender (no. (\%)) } \\
\hline Male & $147(68.1)$ & $145(68.7)$ & $146(66.1)$ & $152(71.0)$ & $590(68.4)$ \\
\hline Female & 69 (31.9) & $66(31.3)$ & 75 (33.9) & $62(29.0)$ & $272(31.6)$ \\
\hline 24-h SBP $(\mathrm{mm} \mathrm{Hg})^{\mathrm{a}}$ & $158.1 \pm 12.3$ & $157.3 \pm 12.6$ & $157.6 \pm 11.8$ & $157.7 \pm 11.5$ & $157.6 \pm 12.0$ \\
\hline 24-h DBP (mm Hg) & $96.6 \pm 8.1$ & $96.6 \pm 8.2$ & $96.5 \pm 8.1$ & $96.9 \pm 8.0$ & $96.6 \pm 8.1$ \\
\hline Seated pulse rate (beats $\min ^{-1}$ ) & $71.0 \pm 7.5$ & $71.1 \pm 9.4$ & $70.9 \pm 8.2$ & $70.1 \pm 7.8$ & $70.8 \pm 8.2$ \\
\hline Body weight $(\mathrm{kg})^{\mathrm{a}}$ & $68.1 \pm 12.6$ & $68.0 \pm 12.6$ & $68.5 \pm 12.7$ & $69.5 \pm 12.5$ & $68.5 \pm 12.6$ \\
\hline $\mathrm{BMI}\left(\mathrm{kg} \mathrm{m}^{-2}\right)^{\mathrm{a}}$ & $25.2 \pm 3.5$ & $25.5 \pm 3.7$ & $25.6 \pm 3.7$ & $25.6 \pm 3.7$ & $25.5 \pm 3.7$ \\
\hline \multicolumn{6}{|l|}{ Severity of hypertension (no. (\%)) } \\
\hline Grade $\mathrm{I}^{\mathrm{b}}$ & $112(51.9)$ & $111(52.6)$ & $116(52.5)$ & $112(52.3)$ & $451(52.3)$ \\
\hline Grade $\|^{\mathrm{b}}$ & $104(48.1)$ & $100(47.4)$ & $105(47.5)$ & $102(47.7)$ & $411(47.7)$ \\
\hline
\end{tabular}

Abbreviations: AZL (16), azelnidipine $16 \mathrm{mg}$; BMI, body mass index; DBP, diastolic blood pressure; FAS, full analysis set; O/A (10/8), olmesartan medoxomil 10 mg/azelnidipine 8 mg; O/A (20/16), olmesartan medoxomil $20 \mathrm{mg} /$ azelnidipine $16 \mathrm{mg}$; OLM (20), olmesartan medoxomil $20 \mathrm{mg}$; SBP, systolic blood pressure. olmesartan medoxomil
aValues are mean \pm s.d

bGrade I, $140 \leqslant \mathrm{SBP} \leqslant 159 \mathrm{~mm} \mathrm{Hg}$ and/or $90 \leqslant \mathrm{DBP} \leqslant 99 \mathrm{~mm} \mathrm{Hg}$; Grade II, $160 \leqslant \mathrm{SBP} \leqslant 179 \mathrm{~mm} \mathrm{Hg}$ and/or $100 \leqslant \mathrm{DBP} \leqslant 109 \mathrm{~mm} \mathrm{Hg}$. 
a

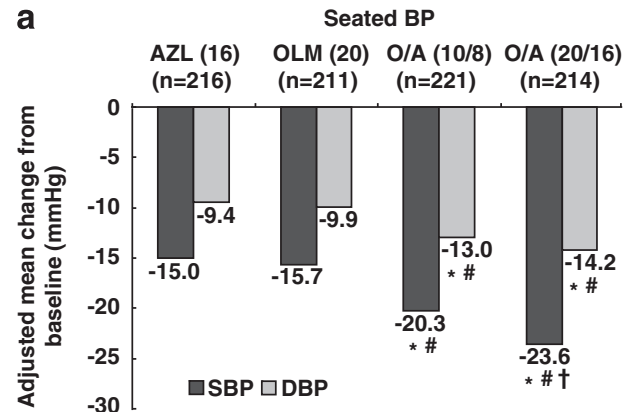

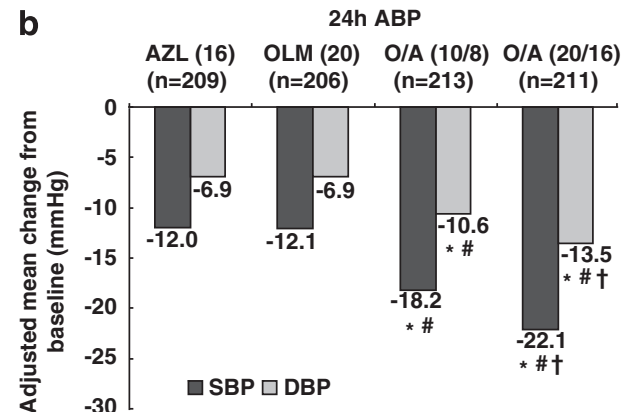

Figure 2 Adjusted mean change from baseline in clinic-seated blood pressure and 24-h mean blood pressure. (a) Seated systolic blood pressure (SBP) and diastolic blood pressure (DBP). (b) Twenty-four-hour mean ambulatory SBP and DBP. BP, blood pressure; ABP, ambulatory blood pressure; AZL (16), azelnidipine $16 \mathrm{mg}$; OLM (20), olmesartan medoxomil $20 \mathrm{mg}$; O/A (10/8), olmesartan medoxomil 10 mg/azelnidipine 8mg; O/A (20/16), olmesartan medoxomil $20 \mathrm{mg} /$ azelnidipine $16 \mathrm{mg} .{ }^{*} P<0.001$ vs. AZL (16); ${ }^{\#} P<0.001 \mathrm{vs}$. OLM (20); ${ }^{\dagger} P<0.001 \mathrm{vs}$. O/A (10/8).
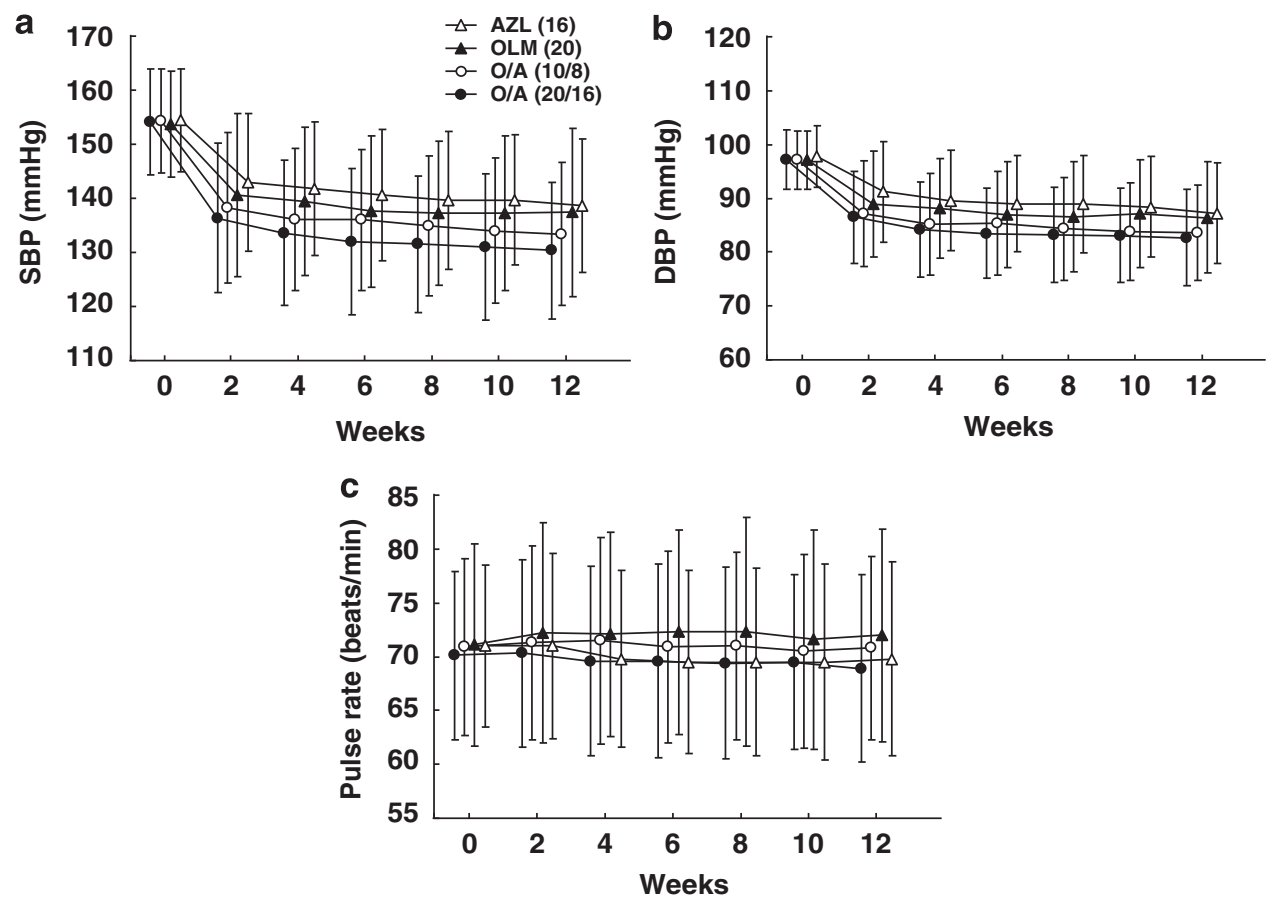

Figure 3 Mean seated blood pressure (mean \pm s.d.) and pulse rate (mean \pm s.d.) after 2, 4, 6, 8, 10 and 12-week treatment. (a) Systolic blood pressure (SBP), (b) diastolic blood pressure (DBP) and (c) pulse rate. AZL (16), azelnidipine $16 \mathrm{mg}$ (open triangles); OLM (20), olmesartan medoxomil $20 \mathrm{mg}$ (closed triangles); O/A (10/8), olmesartan medoxomil $10 \mathrm{mg} /$ azelnidipine $8 \mathrm{mg}$ (open circles); O/A (20/16), olmesartan medoxomil $20 \mathrm{mg} /$ azelnidipine $16 \mathrm{mg}$ (closed circles).

related AEs were dizziness, headache, elevated alanine aminotransferase, elevated aspartate aminotransferase, elevated C-reactive protein and elevated $\gamma$-glutamyl transferase. In the elderly ( $\geqslant 65$ years of age), the incidence of drug-related AEs was $18.5 \%$ (10/54 patients) in the AZL (16) group, $16.7 \%$ (10/60 patients) in the OLM (20) group, $7.4 \%$ (4/54 patients) in the O/A (10/8) group and $4.4 \%$ (2/45 patients) in the O/A (20/16) group. In addition, drug-related AEs corresponding to dizziness, postural dizziness and orthostatic hypotension were evaluated. Such AEs occurred in 2.3, 0.9, 0 and 2.3\% of patients in the AZL (16), OLM (20), O/A (10/8) and O/A (20/16), respectively. The incidence of such AEs was low in all groups and was not increased by combination therapy compared with monotherapy.

No patients died during the treatment period. Serious AEs occurred in 10 patients, of whom one patient $(\mathrm{O} / \mathrm{A}(10 / 8))$ suffered subarachnoid hemorrhage considered a drug-related AE. Nine patients discontinued treatment because of AEs (AZL (16), $n=5$; OLM (20), $n=2$; O/A (10/8), $n=2 ; \mathrm{O} / \mathrm{A}(20 / 16), n=0)$. These AEs were not related to the study drug, with the exception of one event each, that is, subarachnoid hemorrhage in the O/A (10/8) group and nausea in the AZL (16) group. Discontinuation of treatment because of AEs was not increased by combination therapy.

\section{DISCUSSION}

This study was conducted to evaluate the antihypertensive effect and the safety of O/A (20/16) combination compared with OLM $20 \mathrm{mg}$ or AZL $16 \mathrm{mg}$ monotherapy in Japanese patients with essential hypertension. These usual doses in Japan were selected as higher doses in this study. In addition, O/A (10/8) combination was also investigated. 
These doses were selected as low-dose combination because they are the starting doses according to the package inserts in Japan. The reduction in SeBP and 24-h BP by both high-dose and low-dose

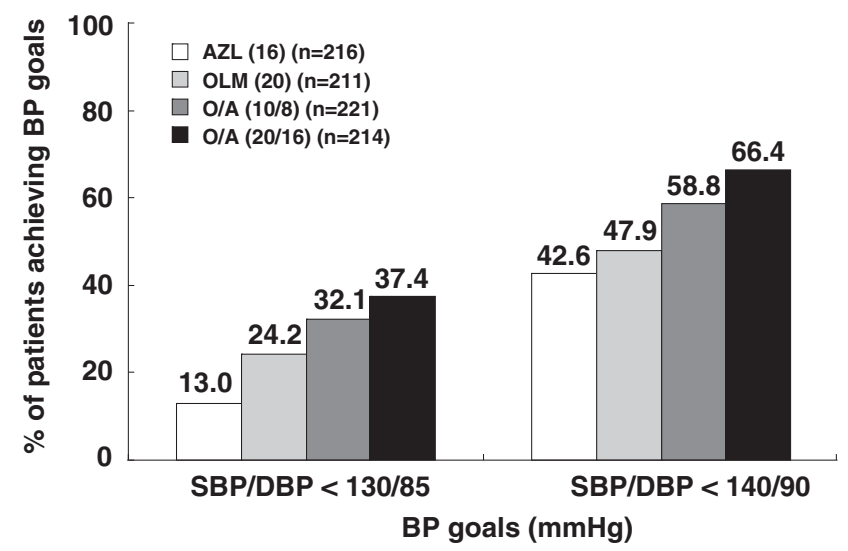

Figure 4 Proportions of patients achieving the seated blood pressure goal at week 12. BP, blood pressure; SBP, systolic blood pressure; DBP, diastolic blood pressure; AZL (16), azelnidipine $16 \mathrm{mg}$; OLM (20), olmesartan medoxomil $20 \mathrm{mg}$; O/A (10/8), olmesartan medoxomil $10 \mathrm{mg} /$ azelnidipine $8 \mathrm{mg}$; O/A (20/16), olmesartan medoxomil $20 \mathrm{mg} /$ azelnidipine $16 \mathrm{mg}$. combination therapy were significantly greater than OLM $20 \mathrm{mg}$ or AZL $16 \mathrm{mg}$ monotherapy.

The target BP in the guidelines for management of hypertension is $<140 / 90 \mathrm{~mm} \mathrm{Hg}$ in the United States and Europe. ${ }^{2,4}$ In Japan, it is $<130 / 85 \mathrm{mmHg}$ in young/middle-aged patients and $<140 /$ $90 \mathrm{~mm} \mathrm{Hg}$ in the elderly. ${ }^{5}$ In many cases, antihypertensive treatment to achieve the BP goal requires the concomitant use of two or more drugs with different mechanisms of action. As this study confirmed that $\mathrm{O} / \mathrm{A}$ combination therapy showed the higher rates of achievement of target SeBP than each monotherapy, it would be useful for more strict BP control.

Twenty-four-hour ambulatory BP has been shown to be more closely correlated with the severity of organ damage compared with clinic BP. ${ }^{14}$ ABPM is a reliable method for evaluating the 24 -h effects of antihypertensive drugs and is suitable for evaluating the effects of once-a-day antihypertensive drugs. The $\mathrm{BP}$ in the O/A combination groups was well controlled for $24 \mathrm{~h}$ in this study. This shows that $\mathrm{O} / \mathrm{A}$ combination therapy is capable of strict BP control that persists for $24 \mathrm{~h}$.

Both OLM and AZL originated in Japan and have been developed as a more effective antihypertensive ARB than other ARBs and a longacting dihydropyridine $\mathrm{CCB}$, respectively. ${ }^{15,16}$ In addition to reducing BP, OLM is reported to have the following effects: inhibition of vascular remodeling, anti-inflammatory effect, antiatherosclerotic

Table 2 Clinical and laboratory adverse event (AE) summary

\begin{tabular}{|c|c|c|c|c|c|c|c|c|}
\hline & $\begin{array}{l}A Z L(16) \\
(n=217)\end{array}$ & & $\begin{array}{l}\text { OLM (20) } \\
(\mathrm{n}=213)\end{array}$ & & $\begin{array}{c}O / A(10 / 8) \\
(n=221)\end{array}$ & & $\begin{array}{c}O / A(20 / 16) \\
(n=215)\end{array}$ & \\
\hline$A / / A E$ & $126(58.1)$ & & $127(59.6)$ & & $115(52.0)$ & & $124(57.7)$ & \\
\hline Drug-related $\mathrm{AE}$ & $34(15.7)$ & & $23(10.8)$ & & $15(6.8)$ & & $22(10.2)$ & \\
\hline Discontinuation due to $\mathrm{AE}$ & $5(2.3)$ & & $2(0.9)$ & & $2(0.9)$ & & $0(0.0)$ & \\
\hline Clinical AE & 107 (49.3) & & $118(55.4)$ & & $100(45.2)$ & & $114(53.0)$ & \\
\hline Drug-related clinical $\mathrm{AE}$ & $16(7.4)$ & & $9(4.2)$ & & $6(2.7)$ & & $13(6.0)$ & \\
\hline \multicolumn{9}{|l|}{$\begin{array}{l}\text { Most common clinical AEs } \\
\text { (incidence }>2 \% \text { in any treatment group) }\end{array}$} \\
\hline Diarrhea & $6(2.8)$ & {$[2(0.9)]$} & $5(2.3)$ & {$[0(0.0)]$} & $7(3.2)$ & {$[0(0.0)]$} & $4(1.9)$ & {$[0(0.0)]$} \\
\hline Gastroenteritis & $2(0.9)$ & {$[0(0.0)]$} & $2(0.9)$ & [0 (0.0)] & $1(0.5)$ & [0 (0.0)] & $7(3.3)$ & [0 (0.0)] \\
\hline Nasopharyngitis & $38(17.5)$ & {$[0(0.0)]$} & $44(20.7)$ & {$[0(0.0)]$} & $46(20.8)$ & {$[0(0.0)]$} & $48(22.3)$ & {$[0(0.0)]$} \\
\hline Contusion & $3(1.4)$ & {$[0(0.0)]$} & $5(2.3)$ & {$[0(0.0)]$} & $2(0.9)$ & {$[0(0.0)]$} & $1(0.5)$ & {$[0(0.0)]$} \\
\hline Back pain & $7(3.2)$ & {$[0(0.0)]$} & $2(0.9)$ & [0 (0.0)] & $4(1.8)$ & {$[0(0.0)]$} & $3(1.4)$ & {$[0(0.0)]$} \\
\hline Dizziness & $7(3.2)$ & [4 (1.8)] & $6(2.8)$ & {$[1(0.5)]$} & $5(2.3)$ & {$[0(0.0)]$} & $3(1.4)$ & [2 (0.9)] \\
\hline Headache & $4(1.8)$ & {$[0(0.0)]$} & $10(4.7)$ & {$[1(0.5)]$} & $5(2.3)$ & {$[3(1.4)]$} & $5(2.3)$ & [2 (0.9)] \\
\hline \multirow[t]{2}{*}{ Upper respiratory tract inflammation } & $7(3.2)$ & {$[0(0.0)]$} & $10(4.7)$ & {$[0(0.0)]$} & $4(1.8)$ & {$[0(0.0)]$} & $5(2.3)$ & {$[0(0.0)]$} \\
\hline & $(n=217)$ & & $(n=211)$ & & $(n=220)$ & & $(n=215)$ & \\
\hline Laboratory AE & $44(20.3)$ & & $29(13.7)$ & & $32(14.5)$ & & $30(14.0)$ & \\
\hline Drug-related laboratory $\mathrm{AE}$ & $20(9.2)$ & & $15(7.1)$ & & $9(4.1)$ & & $11(5.1)$ & \\
\hline \multicolumn{9}{|c|}{$\begin{array}{l}\text { Most common laboratory AEs } \\
\text { (incidence }>2 \% \text { in any treatment group) }\end{array}$} \\
\hline ALT increased & $8(3.7)$ & {$[5(2.3)]$} & $6(2.8)$ & {$[6(2.8)]$} & $6(2.7)$ & {$[3(1.4)]$} & $5(2.3)$ & {$[2(0.9)]$} \\
\hline AST increased & $3(1.4)$ & {$[1(0.5)]$} & $5(2.4)$ & {$[5(2.4)]$} & $3(1.4)$ & [0 (0.0)] & $2(0.9)$ & {$[1(0.5)]$} \\
\hline Blood creatine kinase increased & $6(2.8)$ & {$[2(0.9)]$} & $4(1.9)$ & {$[1(0.5)]$} & $3(1.4)$ & {$[0(0.0)]$} & $6(2.8)$ & {$[1(0.5)]$} \\
\hline Blood TG increased & $2(0.9)$ & {$[0(0.0)]$} & $3(1.4)$ & {$[1(0.5)]$} & $6(2.7)$ & {$[0(0.0)]$} & $2(0.9)$ & [0 (0.0)] \\
\hline CRP increased & $9(4.1)$ & [3 (1.4)] & $6(2.8)$ & {$[1(0.5)]$} & $3(1.4)$ & {$[1(0.5)]$} & $8(3.7)$ & {$[1(0.5)]$} \\
\hline$\gamma$-GT increased & $6(2.8)$ & {$[4(1.8)]$} & $3(1.4)$ & {$[2(0.9)]$} & $6(2.7)$ & {$[3(1.4)]$} & $5(2.3)$ & [3 (1.4)] \\
\hline White blood cells in urine: positive & $5(2.3)$ & {$[0(0.0)]$} & $3(1.4)$ & {$[1(0.5)]$} & $4(1.8)$ & {$[0(0.0)]$} & $4(1.9)$ & [1 (0.5)] \\
\hline
\end{tabular}

Abbreviations: ALT, alanine aminotransferase; AST, aspartate aminotransferase; AZL (16), azelnidipine $16 \mathrm{mg}$; CRP, C-reactive protein; $\gamma$-GT, $\gamma$-glutamyl transferase; O/A (10/8), olmesartan medoxomil $10 \mathrm{mg} /$ azelnidipine $8 \mathrm{mg}$; O/A (20/16), olmesartan medoxomil $20 \mathrm{mg} /$ azelnidipine $16 \mathrm{mg}$; OLM (20), olmesartan medoxomil $20 \mathrm{mg}$; TG, triglyceride.

Values are number (\%) of patients. Numbers (\%) in brackets indicate numbers (\%) of AEs considered by the investigator to be possibly, probably or definitely study drug-related. 
effect, maintaining cerebral blood flow and prevention of microalbuminuria. ${ }^{17-20}$ AZL is also reported to have the following effects: antioxidative effect, antiatherosclerotic effect, maintaining cerebral blood flow, prevention of proteinuria and PR reduction which is not observed with amlodipine. ${ }^{21-25}$ Furthermore, combined use of $\mathrm{ARB}$ and AZL is reported to prevent microalbuminuria in diabetic nephropathy patients. ${ }^{26}$ A nonclinical study demonstrated that OLM plus $\mathrm{CCB}$ combination showed the various preventive effects on vascular injury depending on which $\mathrm{CCB}$ was used; AZL was the most effective CCB tested. ${ }^{27}$ In addition, O/A combination has been reported to have an antiatherosclerotic effect and an inhibitory effect on ischemic brain damage in nonclinical studies. ${ }^{28,29}$ These reports suggest that combination of $\mathrm{O} / \mathrm{A}$ is not only highly effective in reducing BP, but may also protect organs. The COLM study, currently being conducted in Japan, will compare the effects of combination of OLM plus a low-dose diuretic with those of OLM plus a CCB in preventing cardiovascular events in high-risk elderly hypertensive patients. ${ }^{30}$

The incidence of AEs in the O/A combination groups was similar to that of the monotherapy groups, and the combination therapy showed a potent antihypertensive effect without an increase in the incidence of AEs. In the elderly ( $\geqslant 65$ years of age), the incidence of AEs in the O/A combination groups was similar to that in younger individuals, and safety risk was not increased. The incidence of AEs possibly caused by excessive reduction in BP (dizziness, postural dizziness or orthostatic hypotension) was not increased by $\mathrm{O} / \mathrm{A}$ combination compared with monotherapy. The mean PR in the O/A group showed little change throughout the study, and actually, it tended to decrease. This suggests that the combination of O/A exerts a potent antihypertensive effect without reflex tachycardia. Thus, combination therapy with $\mathrm{O} / \mathrm{A}$ is well tolerated and considered safe.

We concluded that O/A combination therapy was well tolerated in patients with essential hypertension, and the antihypertensive effect was greater than that of OLM or AZL monotherapy. This ARB/CCB combination of $\mathrm{O} / \mathrm{A}$, therefore, could be a useful treatment option for essential hypertension.

\section{ACKNOWLEDGEMENTS}

This study was supported by Daiichi Sankyo (Tokyo, Japan). We acknowledge the investigators and other staff members who participated in this study. The study centers and investigators were as follows: Hidehisa Nakagawa, MD, Nakagawa Medical Clinic; Katsuhiro Matsuda, MD, MATSUDA Medical Clinic; Kazuko Takahashi, MD, Takahashi Clinic; Yutaka Kadono, MD, Kadono Clinic; Yasuhiro Nakamura, MD, Kitanodohri Naika Junkanki Clinic; Teruaki Mita, MD, Mita Medical-Cardiovascular Clinic; Shigemichi Tanaka, MD, Naoki Kishida, MD, Hideki Takizawa, MD, Izumi Yamaji, MD, Teine Keijinkai Clinic; Fumiaki Nakazawa, MD, Shinkotoni Family Clinic; Masami Kogure, MD, KOGURE Clinic; Chiharu Iguchi, MD, Iguchi Clinic; Shuichi Ichikawa, MD, Yoshiaki Takayama, MD, Cardiovascular Hospital of Central Japan; Izuru Kobayashi, MD, Kobayashi Clinic of Internal Medicine and Gastroenterology; Shintaro Yano, MD, Haruo Kono, MD, Masaru Sakai, MD, Maebashi Hirosegawa Clinic; Masanori Shitaya, MD, Yoji Date, MD, Satoshi Mori, MD, Chiaki Noguchi, MD, Makoto Arai, MD, Haruhiko Nishizawa, MD, Shinozaki ekimae Clinic; Kazuo Suzuki, MD, Kenkoukan Suzuki Clinic; Otoya Miho, MD, Miho Clinic; Hiroshi Shimomura, MD, Medical Corp. Junyo-kai, Musashino Clinic; Yoshihisa Abo, MD, Kitaaoyama D. Clinic; Akira Numata, MD, Ikebukuro Metropolitan Clinic; Fumiaki Nishimura, MD, Nishimura Naika Jyunkankika Clinic; Syuuro Kondo, MD, Hajime Onda, MD, Osamu Matsuoka, MD, Makoto Kawai, MD, Mie Kawai, MD, Makoto Akaishi, MD, Megumu Shimada, MD, Akiyasu Baba, MD, Mami Kiso, MD, Yoko Kitagawa, MD, Kazuko Muto, MD, Tokyo Clinical Research Organisation for Medicine Clinic; Munechika Noguchi, MD, Yotaro Takaku, MD, Shinagawa East One Medical Clinic; Masaaki Kawamura, MD, Medical Corp. Kohsei-kai, Kawamura Naika; Masami
Fujita, MD, Takeshi Adachi, MD, Yoshiaki Kikuchi, MD, Hideyuki Kobayashi, MD, Mika Kobayashi, MD, Medical Corporation Shinanokai SHINANOZAKA CLINIC; Masafumi Sugawara, MD, Dynamedical Nezu Clinic; Hideki Kaizuka, MD, Pedi Shiodome Clinic; Hirotaka Nagashima, MD, Tokyo Heart Center; Takeaki Komine, MD, Komine Clinic; Yoji Takatsuka, MD, Motomachi Takatsuka Naika Clinic; Hiroyuki Ameno, MD, Medical Corp Shoyu-kai, Ameno Clinic; Masahiko Kondo, MD, Medical Corp. Kondo Clinic; Hiroshi Mikami, MD, Yasushi Fujio, MD, Yoshihiro Maekawa, MD, Mitsuru Oishi, MD, Hidetoshi Osawa, MD, Noriko Saigo, MD, Ken Sugimoto, MD, Michio Yagi, MD, Tsutomu Sakurai, MD, Osaka Pharmacology Clinical Research Hospital; Shigeto Kanada, MD, OCROM Clinic; Koichi Fukuda, MD, Taro Saito, MD, Toru Higa, MD, Kaichiro Hiroshige, MD, Toru Kakazu, MD, Ayuko Kuroiwa, MD, Ai Masuya, MD, Naoto Miyagi, MD, Keita Nakamura, MD, Tomoko Noda, MD, Fukuoka Wajiro Hospital; Yuichiro Nakamura, MD, Nakamura Cardiovascular Clinic; Ryuuji Yoshimura, MD, Yoshimura Internal Medicine; Shigeru Fuji, MD, Tadao Kuruma, MD, Hirotaka Miyazono, MD, Fukuoka Shin Mizumaki Hospital; and Nobukuni Yoshida, MD, Riko Yoshida, MD, Momochihama Clinic.

1 Lewington S, Clarke R, Qizilbash N, Peto R, Collins R. Prospective Studies Collaboration. Age-specific relevance of usual blood pressure to vascular mortality: a metaanalysis of individual data for one million adults in 61 prospective studies. Lancet 2002; 360: 1903-1913

2 Chobanian AV, Bakris GL, Black HR, Cushman WC, Green LA, Izzo Jr JL, Jones DW, Materson BJ, Oparil S, Wright Jr JT, Roccella EJ. The Seventh Report of the Joint National Committee on Prevention, Detection, Evaluation, and Treatment of High Blood Pressure: the JNC 7 report. JAMA 2003; 289: 2560-2572.

3 Mori H, Ukai H, Yamamoto H, Saitou S, Hirao K, Yamauchi M, Umemura S. Current status of antihypertensive prescription and associated blood pressure control in Japan. Hypertens Res 2006; 29: 143-151.

4 Mancia G, De Backer G, Dominiczak A, Cifkova R, Fagard R, Germano G, Grassi G, Heagerty AM, Kjeldsen SE, Laurent S, Narkiewicz K, Ruilope L, Rynkiewicz A, Schmieder RE, Struijker Boudier HA, Zanchetti A. 2007 Guidelines for the management of arterial hypertension. Eur Heart J 2007; 28: 1462-1536.

5 The Japanese Society of Hypertension Committee. The Japanese Society of Hypertension Guidelines for the Management of Hypertension (JSH 2009). Hypertens Res 2009; 32: 3-107.

6 Philipp T, Smith TR, Glazer R, Wernsing M, Yen J, Jin J, Schneider H, Pospiech R. Two multicenter, 8-week, randomized, double-blind, placebo-controlled, parallel-group studies evaluating the efficacy and tolerability of amlodipine and valsartan in combination and as monotherapy in adult patients with mild to moderate essential hypertension. Clin Ther 2007; 29: 563-580.

7 Chrysant SG, Melino M, Karki S, Lee J, Heyrman R. The combination of olmesartan medoxomil and amlodipine besylate in controlling high blood pressure: $\mathrm{COACH}$, a randomized, double-blind, placebo-controlled, 8-week factorial efficacy and safety study. Clin Ther 2008; 30: 587-604.

8 Ciulla MM, Paliotti R, Esposito A, Diez J, López B, Dahlöf B, Nicholls MG, Smith RD, Gilles L, Magrini F, Zanchetti A. Different effects of antihypertensive therapies based on losartan or atenolol on ultrasound and biochemical markers of myocardial fibrosis: results of a randomized trial. Circulation 2004; 110: 552-557.

9 Brenner BM, Cooper ME, de Zeeuw D, Keane WF, Mitch WE, Parving HH, Remuzzi G, Snapinn SM, Zhang Z, Shahinfar S. RENAAL Study Investigators. Effects of losartan on renal and cardiovascular outcomes in patients with type 2 diabetes and nephropathy. N Engl J Med 2001; 345: 861-869.

10 Terpstra WF, May JF, Smit AJ, de Graeff PA, Havinga TK, van den Veur E, Schuurman $\mathrm{FH}$, Meyboom-de Jong B, Crijns HJ. Long-term effects of amlodipine and lisinopril on left ventricular mass and diastolic function in elderly, previously untreated hypertensive patients: the ELVERA trial. J hypertens 2001; 19: 303-309.

11 Pitt B, Byington RP, Furberg CD, Hunninghake DB, Mancini GB, Miller ME, Riley W. Effect of amlodipine on the progression of atherosclerosis and the occurrence of clinical events. Circulation 2000; 102: 1503-1510.

12 Jamerson K, Weber MA, Bakris GL, Dahlöf B, Pitt B, Shi V, Hester A, Gupte J, Gatlin M, Velazquez EJ. ACCOMPLISH Trial Investigators. Benazepril plus amlodipine or hydrochlorothiazide for hypertension in high-risk patients. N Engl J Med 2008; 359: 2417-2428.

13 Minami J, Ishimitsu T, Iwase T, Koshikawa C. Prescribing trends in antihypertensive drugs. Nippon Rinsho 2006; 64(Suppl 6): 247-253 (in Japanese).

14 Mancia G, Zanchetti A, Agabiti-Rosei E, Benemio G, De Cesaris R, Fogari R, Pessina A, Porcellati C, Rappelli A, Salvetti A, Trimarco B. Ambulatory blood pressure is superior to clinic blood pressure in predicting treatment-induced regression of left ventricular hypertrophy. Circulation 1997; 95: 1464-1470.

15 Oparil S. Comparative antihypertensive efficacy of Olmesartan: comparison with other angiotensin II receptor antagonists. J Hum Hypertens 2002; 16(Suppl 2): S17-S23. 16 Wellington K, Scott LJ. Azelnidipine. Drugs 2003; 63: 2613-2621. 
17 Fliser D, Buchholz K, Haller H. Antiinflammatory effects of angiotensin II subtype 1 receptor blockade in hypertensive patients with microinflammation. Circulation 2004; 110: 1103-1107.

18 Stumpe KO, Agabiti-Rosei E, Zielinski T, Schremmer D, Scholze J, Laeis P, Schwandt P, Ludwig M. Carotid intima-media thickness and plaque volume changes following 2-year angiotensin II-receptor blockade. The Multicentre OImesartan atherosclerosis Regression Evaluation (MORE) study. Ther Adv Cardiovasc Dis 2007; 1: 97-106.

19 Ikeda H, Hamamoto Y, Honjo S, Nabe K, Wada Y, Koshiyama H. Olmesartan reduced microalbuminuria in Japanese subjects with type 2 diabetes. Diabetes Res Clin Pract 2009; 83: 117-118.

20 Matsumoto S, Shimodozono M, Miyata R, Kawahira K. Benefits of the angiotensin II receptor antagonist olmesartan in controlling hypertension and cerebral hemodynamics after stroke. Hypertens Res (e-pub ahead of print 11 September 2009; doi:10.1038/ hr.2009.143).

21 Kimura Y, Kitagawa K, Oku N, Kajimoto K, Kato H, Tanaka M, Sakaguchi M, Hougaku $\mathrm{H}$, Sakoda S, Hatazawa J. Hemodynamic influences of azelnidipine, a novel calcium channel blocker, on cerebral circulation in hypertensive patients with ischemic white matter lesions. Hypertens Res 2008; 31: 2147-2154.

22 Nakamura T, Sugaya T, Kawagoe Y, Suzuki T, Ueda Y, Koide H, Inoue T, Node K. Azelnidipine reduces urinary protein excretion and urinary liver-type fatty acid binding protein in patients with hypertensive chronic kidney disease. Am J Med Sci 2007; 333: 321-326.

23 Ogawa S, Mori T, Nako K, Ito S. Combination therapy with renin-angiotensin system inhibitors and the calcium channel blocker azelnidipine decreases plasma inflammatory markers and urinary oxidative stress markers in patients with diabetic nephropathy. Hypertens Res 2008; 31: 1147-1155.
24 Nada T, Nomura M, Koshiba K, Kawano T, Mikawa J, Ito S. Clinical study with azelnidipine in patients with essential hypertension. Antiarteriosclerotic and cardiac hypertrophy-inhibitory effects and influence on autonomic nervous activity. Arzneimittelforschung 2007; 57: 698-704.

25 Kuramoto K, Ichikawa S, Hirai A, Kanada S, Nakachi T, Ogihara T. Azelnidipine and amlodipine: a comparison of their pharmacokinetics and effects on ambulatory blood pressure. Hypertens Res 2003; 26: 201-208.

26 Nakamura T, Inoue T, Fujiwara N, Kawagoe Y, Sugaya T, Ueda Y, Koide H, Node K. Additional renoprotective effects of azelnidipine combined with angiotensin receptor blockers in patients with diabetic nephropathy. Clin Nephrol 2008; 70: 385-392.

27 Inaba S, Iwai M, Tomono Y, Senba I, Furuno M, Kanno H, Okayama H, Mogi M, Higaki J, Horiuchi M. Prevention of vascular injury by combination of an AT1 receptor blocker, olmesartan, with various calcium antagonists. Am J Hypertens 2009; 22: 145-150.

28 Jinno T, Iwai M, Li Z, Li JM, Liu HW, Cui TX, Rakugi H, Ogihara T, Horiuchi M. Calcium channel blocker azelnidipine enhances vascular protective effects of AT1 receptor blocker olmesartan. Hypertension 2004; 43: 263-269.

29 Iwai M, Chen R, Ide A, Iwanami J, Tomochika H, Tomono Y, Mogi M, Horiuchi M. The calcium-channel blocker, azelnidipine, enhances the inhibitory action of AT1 receptor blockade on ischemic brain damage. J Hypertens 2006; 24: 2023-2031.

30 Ogihara T, Saruta T, Rakugi H, Shimamoto K, Ito S, Matsuoka H, Horiuchi M, Imaizumi T, Takishita S, Higaki J, Katayama S, Saito I, Shimada K. Rationale, study design and implementation of the COLM study: the combination of olmesartan and calcium channel blocker or diuretic in high-risk elderly hypertensive patients. Hypertens Res 2009; 32: 163-167. 